\title{
Stability Analysis and Chaos Control of Recycling Price Game Model for Manufacturers and Retailers
}

\author{
Ting Li $\mathbb{D}^{1,2}$ Dongyun Yan, ${ }^{2}$ and Xiaogang $\mathrm{Ma}^{3}$ \\ ${ }^{1}$ School of Management, Shandong University, Jinan 250100, China \\ ${ }^{2}$ School of Economics and Management, Dezhou University, Dezhou 253023, China \\ ${ }^{3}$ School of Management, Wuhan Textile University, Wuhan 430200, China \\ Correspondence should be addressed to Ting Li; tjulit@foxmail.com
}

Received 27 March 2019; Revised 14 June 2019; Accepted 26 June 2019; Published 24 July 2019

Academic Editor: Marcio Eisencraft

Copyright (c) 2019 Ting Li et al. This is an open access article distributed under the Creative Commons Attribution License, which permits unrestricted use, distribution, and reproduction in any medium, provided the original work is properly cited.

\begin{abstract}
With application of nonlinear theory, this paper makes study on the long-term competition in a recycling price game model by manufacturers and retailers. The paper makes analysis on the local stability of the Nash equilibrium point and gives the corresponding stable region. It has been found that the stability of the whole system would be significantly impacted by the following factors which include adjustment speed of the recycling price, the proportion of recycled products by channels, the sensitivity of consumers for the recycling price, and the price cross-elasticity between two channels. By means of the simulation technology, the complexity of the recycling price in the system in the long-term competition has been demonstrated. Owing to the change of parameters, bifurcation, chaos, and other phenomena would appear in the system. When the system is becoming chaotic, the profit of the whole system decreased. All these show that the operational efficiency for the whole system will be impaired by the chaos. Effective chaotic control of the system will be realized by the use of the parameter adaptation method.
\end{abstract}

\section{Introduction}

The natural environmental pollution caused by industrial development for centuries has been spreading for decades. With increase of people's environmental awareness, the reverse supply chain based on recycling and remanufacturing of recycled products has become more increasingly necessary.

Some scholars have conducted extensive research on relevant problems about close-loop supply chain: selection of recollection channels, selection of sales channels, pricing and coordination, net designing, and so on. There mainly exist two categories of research: the first one is product competition, that is, the competition between new products and remanufactured products for the same manufacturer; the second one is the competition of members in the supply chain, that is, the competition between the manufacturer and the remanufacturer for the same product. Savaskan et al. [1,2] and Chuang et al. [3] established a closed-loop supply chain model which includes three types of recycling led, respectively, by the producer, the retailer, and the thirdparty. They also make study on the pricing strategies and performance-comparison analysis for each member. Ferrer et al. $[4,5]$ made study on the pricing decisions of competitive closed-loop supply chains between manufacturers and remanufacturers. Karakayal et al. [6] made research on the decontamination and recycling operations of waste products in the consumer durables industry. Models were established to make argumentation on (1) the optimal recycling price of waste products and the optimal retailing price of recycled products in the consumer durables industry and (2) on the ways in which coordination could be realized to keep the recovery rate at the similar level in both centralized and decentralized decision-making circumstances. Analysis has been made on the specific time when OEM is more willing to outsource the process of recycling or disposing of used products. On the basis of relevant data in the Japanese automarket Kumar et al. constructed a closed-loop supply chain model and made predication on the relationship between vehicle recycling and disposal. Adda et al. [7] made comparison on the advantages and disadvantages of the three pricing strategies and revealed the impacts of product durability, consumer composition, product life cycle, and 
recycling revenue on the optimal pricing and "trade-in" discounts. Ma et al. [8] discussed the impact of government "trade-in" subsidies on consumers, manufacturers, retailers, and size of closed-loop supply chains in the two-channel closed-loop supply chain system. Huang et al. [9] discussed a closed-loop supply chain for dual recycling channels: that is, in the forward logistics, the manufacturer sells products through the retailer, while, in the reverse logistics, the retailer and the third party compete simultaneously to collect waste products. They also made comparison on the optimal strategies in both dual recycling channel and single recycling channel (including the retailer or the third party) with the result that the parameter domain of the competitive strength was deducted when the dual recycling channel was superior to the single recycling channel, respectively, from the perspectives of both the manufacturer and the consumer. $\mathrm{Zu}$ et al. [10] established a three-tier supply chain consisting of one manufacturer, one retailer, and two recyclers for the purpose of discussing how different cooperative strategy structures could affect the decision-making of closed-loop supply chains. It turns out that the cooperation strategy could create the win-win situation, improve the profit of the partners, and realize the higher efficiency from the perspective of the entire supply chain. Furthermore, they conducted research on cooperative games and noncooperative games (manufacturer-led), supplied the optimal strategy in these two cases, and compared the results with those mentioned in the literature [2], which have provided a theoretical basis for the choice of recycling channels by the decision-makers. With the rapid development of modern communication technology, the direct-to-consumers retail industry in the circulation terminal has experienced a dramatic change. Large-scaled supermarkets such as Wal-Mart and Carrefour occupy a large share of the consumer goods market, while large-scaled electrical retailers such as Gome and Suning (with their branches across the country) have been in the position of monopoly in the home appliance sales market. The supply chain will be greatly impacted by the retailers. It has been of great necessity to study the relevant issues about the supply chain led by retailers. Maiti et al. [11] also have proved that when retailers are the market leaders, greater profits will be available to all members in the channel. Under the condition of retailers being in the leading market position, as the market leaders many scholars have established a hybrid recycling channel model in which recycling was made jointly by manufacturers and retailers, discussed the optimal strategy for the recycling by both the retailers-led manufacturers and retailers in the hybrid recycling model, and finally made analysis on the relationship between decision-making by the channel members and recycling price.

The economic system, with people being involved in, is a complex and open system with information feedback capabilities. For a nonlinear system, its subsystems, when they are being combined, will not have a simple linear additive effect on the whole system; they will be mutually coupled which makes the system produce a qualitative change and show the nature and characteristics that the original subsystem does not have. Research on the oligopoly game model and its complexity has attracted attention of scholars for many years. In an oligarch competition, the firms are either output or price setters; see the studies by Cournot [12] and Bertrand [13]. Theocharis [14] found a classic conclusion that, under discrete time scales and static expectations, the equilibrium of a single product oligopoly with linear price and cost functions, without any product differentiation, will be asymptotically stable if and only if it is a duopoly. Rand [15] found that, in the game of the Cournot model, the result of the oligopolistic game may not converge to the Nash equilibrium point but produce a periodic solution or a chaotic solution. Since then a large number of scholars carried out further research and improvement on the Cournot model, introduced bounded rationality and incomplete information into the model, and studied its complex behavior. On the basis of the classical Cournot model, Puu et al. [16, 17] made study on the yield adjustment process under the equal elastic demand function and obtained similar conclusions. Bischi et al. [18, 19] studied the Cournot game model which is bounded with rationality and also made research on the influence of output adjustment speed on the system stability with analysis on the critical curve and the attraction domain of Nash equilibrium point. Agiza et al. [20] made study on the problem of chaotic synchronization in the Cournot model. They assumed the existence of two identical competitors in the model, studied the mapping symmetry of this model, and found complex dynamic behaviors in the model. With study on the nonlinear cost and introduction of the bounded rational expectation, Ahmed et al. [21, 22] improved the demand function on the basis of which the duopoly game model was to be established and then the duopoly model would be extended to the multidimensional model. It could be concluded that when the game party makes adjustments to the market too fast, the system would present the complex phenomena such as bifurcation and chaos. Elsadany [23] made introduction of delayed decision-making into the Cournot model. They found that the introduction of appropriate delay strategies could make the system more stable without changing the Nash equilibrium point for the whole system. Some scholars have also made the study on supply chain competition by using nonlinear dynamics theory. Li et al. $[24,25]$ and Li et al. $[26,27]$ studied the long-term price competition in the multichannel supply chain and found complex phenomena such as bifurcation and chaos. Ma et al. [28, 29] studied the chaotic phenomenon in the closed-loop supply chain and performed effective chaotic control for the system.

For many economic management systems, chaos is detrimental to the system operation. Therefore, effective methods should be employed for suppressing chaos in accordance with the characteristics of the system itself. Many scholars proposed a variety of methods for chaos controlling, such as OGY method, controlling method for variable feedback, and controlling method for delayed feedback. At present, two methods are mainly employed for chaos control [30, 31]: (1) The modification of the parameters is used to control the chaotic system; (2) the modification of the variables for the system state is used to suppress the chaos occurrence. The OGY method [32] was the first method proposed to suppress the chaos occurrence. Subsequently, many scholars have proposed a series of chaotic control methods, such as 


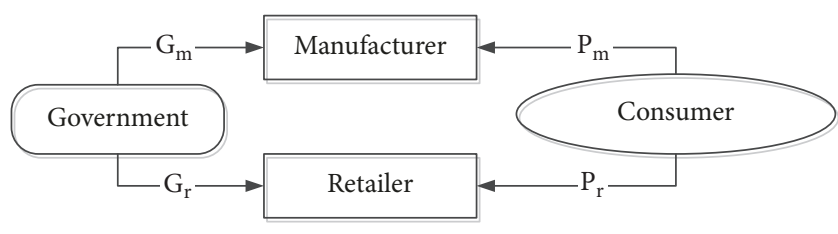

FIgURE 1: The structure of the supply chain.

method for perturbation of parameter cycle [33], OPF control method [34], and control method for continuous feedback [35]. In recent years, a new supply chain model and its synchronization behavior have been applied to modeling and analyzing the chaotic behavior in supply chain networks, such as control and synchronization of chaotic supply chains using intelligent approaches [36] and synchronization and control of chaos in supply chain management [37].

Based on the previous research, for the recycling price this paper established a game model consisting of only one manufacturer and one retailer. Under the circumstances of not fully obtaining market information for the manufacturers and retailers, this paper studied the influence of various parameters on the stability of the system by using the pricing strategy of limited rationality and evaluated the operational performance of the system by taking the system profit as the index.

The structure of the paper is as follows: in the second part, we constructed the corresponding model and made analysis on each parameter; in the third part, the local stability of the Nash equilibrium point has been analyzed; in the fourth part, the characteristics of the system in the long-term competition process would be discussed with the means of simulation technology, and relevant performance evaluation would be performed; Finally, in the fifth part, the conclusions of the paper would be achieved.

\section{Problem Description and Model Construction}

2.1. Model Description. Nowadays, many manufacturers, in addition to their own recycling work, also require retailers to carry out recycling work in the process of sales. This is mainly because retailers are much closer to the market and consumers that it is more conducive for recycling process. On the other hand, only those large retailers have the advantage of recycling, and their recycling amounts of used products might be unmatched by those small-scaled and fragmented retailers. Therefore, these retailers involved in recycling could have great oligopoly superiority in a recycling market. For example, in the home appliance market, Gome and Suning are two traditional large retailers whose market shares in sales and recycling could be unmatched by other small home appliances. The structure of supply chain is as shown in Figure 1.

2.2. Symbol Description. a represents amount of the used products that the consumer is willing to recycle under the condition that the price is zero; to a certain extent this reflected the consumer's environmental awareness. $s$ represents the proportion of products that the retailer is willing to recycle; this indicates the convenience of the recycling channel and reflects consumer's recognition of the recycling channel.

$p_{m}, p_{r}$, respectively, represent the recycling prices of both the manufacturer and the retailer.

$Q_{m}, Q_{r}$, respectively, represent the recycling amounts of both the manufacturer and the retailer.

$b$ represents the sensitivity of the consumer to the recycling price.

$d$ reflects the price cross-elasticity between the two channels.

$c_{m}, c_{t}$, respectively, reflect the unit cost of the manufacturer and the retailer.

$G_{m}, G_{r}$ represent amount of the government's recycling subsidies distributed to the manufacturer and retailer for each unit of recycled products.

2.3. Model Construction. We assume that in reality the manufacturer and the retailer would recycle used products together. According to the Bertrand game model, the amount of recycled products is relevant to the recycling price; when there exists more than one recycling company, the amount of recycled products will also be related to the recycling channels and prices offered by other retailers. This could be shown by using a model as follows:

$$
\begin{aligned}
Q_{m} & =(1-s) a+b p_{m}-d p_{r} \\
Q_{r} & =s a+b p_{r}-\mathrm{d} p_{m}
\end{aligned}
$$

The model shows that when the retailer in one channel raises the price, the amounts of recycled products will increase. The profits of the manufacturer and the retailer can be indicated as

$$
\begin{aligned}
\pi_{m} & =\left(G_{m}-p_{m}-c_{m}\right) Q_{m} \\
\pi_{r} & =\left(G_{r}-p_{r}-c_{t}\right) Q_{r}
\end{aligned}
$$

From formula (2) we could see that the marginal profits for the manufacturer and the retailer could be, respectively, concluded as

$$
\begin{aligned}
& \frac{\partial \pi_{m}}{\partial p_{m}}=a(s-1)+d p_{r}+b\left(G_{m}-c_{m}-2 p_{m}\right) \\
& \frac{\partial \pi_{r}}{\partial p_{r}}=d p_{m}-s a+b\left(G_{r}-c_{t}-2 p_{r}\right)
\end{aligned}
$$

From formula (3) it could be concluded that

$$
\begin{aligned}
& p_{m}^{*}=\frac{b\left(2 G_{m} b-2 a-2 b c_{m}+2 a s\right)-d\left(b c_{t}-G_{r}+a s\right)}{4 b^{2}-d^{2}} \\
& p_{r}^{*}=\frac{b\left(2 G_{r} b-2 b c_{r}-2 a s\right)-d\left(b c_{m}-G_{m} b+a-a s\right)}{4 b^{2}-d^{2}}
\end{aligned}
$$

The game between the manufacturer and the retailer is a long-term and continuous process. Their relationship could not be adjusted to the optimal position by only game playing. 
The price competition between them is a long-term, repeated, and dynamic process with complexity. In reality, the market information obtained by the retailer is often incomplete for the reason that obtaining more market information obviously requires more costs. In many cases, owing to the distorted and asymmetrical information, perfect information would be rare even if great efforts have been put into the market investigation. We assume that both the manufacturer and the retailer will adopt expectations of bounded rationality. This indicates that the retailer's price decision in the next period relies on a local estimate of the marginal utility for the current period. If the marginal utility is positive in this period, the retailer will raise the price of the next period; if the marginal utility is negative, the retailer will lower the price of the next period. The dynamic adjustment process is as follows:

$$
\begin{aligned}
& p_{m}(t+1)=p_{m}(t)+\alpha_{1} p_{m}(t) \\
& \cdot\left(a(s-1)+d p_{r}(t)+b\left(G_{m}-c_{m}-2 p_{m}(t)\right)\right) \\
& p_{r}(t+1)=p_{r}(t)+\alpha_{2} p_{r}(t) \\
& \cdot\left(d p_{m}(t)-s a+b\left(G_{r}-c_{t}-2 p_{r}(t)\right)\right)
\end{aligned}
$$

\section{Analysis on Complexity of Market Game}

3.1. Market Equilibrium Point. According to the definition of "fixed point," in system (5), we can get four equilibrium solutions of the system through the formula $p_{i}(t+1)=$ $p_{i}(t),(i=m, r)$

$$
\begin{aligned}
& E_{4} \\
& =\left(\frac{b\left(2 G_{m} b-2 a-2 b c_{m}+2 a s\right)-d\left(b c_{t}-G_{r}+a s\right)}{4 b^{2}-d^{2}},\right. \\
& \\
& \left.\frac{b\left(2 G_{r} b-2 b c_{r}-2 a s\right)-d\left(b c_{m}-G_{m} b+a-a s\right)}{4 b^{2}-d^{2}}\right)
\end{aligned}
$$

According to the value range of the parameters, we know that these four equilibrium points are nonnegative and they have their particularly economic significance. Among them, $E_{1}, E_{2}, E_{3}$ represent the boundary equilibrium points; $E_{4}$ represents the system's Nash equilibrium point.

3.2. Analysis on Stability of Nash Equilibrium Point. Jacobian matrix for system (5) is as follows:

$$
\left(\begin{array}{cc}
1+\alpha_{1}\left(a(s-1)+d p_{r}-b p_{m}-b\left(c_{m}-G_{m}+p_{m}\right)\right) & d p_{m} \alpha_{1} \\
d p_{r} \alpha_{2}, & 1+\alpha_{2}\left(G_{r} b-b c_{t}-4 b p_{r}-a s+d p_{m}\right)
\end{array}\right)
$$

Similarly, the equilibrium point $E_{4}$ is substituted into (7), and we get its Jacobian matrix as

$$
J\left(E^{*}\right)=\left(\begin{array}{cc}
1+\alpha_{1} h_{1}, & d p_{m}^{*} \alpha_{1} \\
d p_{r}^{*} \alpha_{2}, & 1+\alpha_{2} h_{2}
\end{array}\right)
$$

Among them,

$$
\begin{aligned}
& h_{1}=a(s-1)+d p_{r}^{*}-b p_{m}^{*}-b\left(c_{m}-G_{m}+p_{m}^{*}\right), \\
& h_{2}=G_{r} b-b c_{t}-4 b p_{r}^{*}-a s+d p_{m}^{*} .
\end{aligned}
$$

Its corresponding characteristic equation is $\lambda^{2}+A \lambda+B=$ 0 , from which we know $A$ and $B$, respectively, correspond to the rank and the trace in the characteristic equation $J\left(E_{4}\right)$. Among them,

$$
\begin{aligned}
& A=1+h_{1} \alpha_{1}+h_{2} \alpha_{2}+h_{3} \alpha_{1} \alpha_{2}, \\
& B=2+h_{1} \alpha_{1}+h_{2} \alpha_{2} .
\end{aligned}
$$

We got this here: $h_{3}=h_{1} h_{2}-d^{2} p_{m}^{*} p_{r}^{*}$.

According to Jury's condition for equilibrium point stability, we obtain the necessary and sufficient conditions for the local stability of the Nash equilibrium point $E_{4}$ :

$$
\begin{aligned}
& F_{1}=1-A+B>0 \\
& F_{2}=1+A+B>0 \\
& F_{3}=1-B>0
\end{aligned}
$$

According to judgment condition for stability of the Nash equilibrium point, in the case of any two conditions being satisfied, the violation of the other one will cause complex dynamic behaviours for the system.

(1) At that time when $F_{1}=0$, the system would generate Fold points. (2) At that time when $F_{2}=0$, the system will produce Flip points. (3) When $F_{3}=0$, the system will generate Neimark-Sacker distribution.

We put $A$ and $B$ into the judgment condition (11) for stability, and we can get

$$
\begin{aligned}
& F_{1}=2-h_{3} \alpha_{1} \alpha_{2}>0 \\
& F_{2}=4+2 h_{1} \alpha_{1}+2 h_{2} \alpha_{2}+h_{3} \alpha_{1} \alpha_{2}>0 \\
& F_{3}=-\left(1+h_{1} \alpha_{1}+h_{2} \alpha_{2}\right)<0
\end{aligned}
$$

At this time, condition (12) defines a stable region for Nash equalization point $E_{4}$ in the $\left(\alpha_{1}, \alpha_{2}\right)$ plane, and $E_{4}$ is locally asymptotically stable in the area described in condition (12). Once the value for $\alpha_{1}, \alpha_{2}$ exceeds this range, the Nash equilibrium point $E_{4}$ will become unstable. This shows that, for both the network manufacturer and the retailer, when they continue to speed up the price adjustment in order to obtain greater profits, the market competition will become disorderly.

From the perspective of our actual competition, we could give economic significance to the stability of the four equilibrium points in the market. (1) When the Nash equilibrium point is at $E_{1}$, prices for both the manufacturer 
and the retailer will be at zero point, which means that, in the recycling market, neither manufacturers nor retailers have recycled products. When recycling can generate revenue, such a market equilibrium is obviously unstable or even impossible, so the system is unstable at this point $E_{1}$. (2) When the Nash equilibrium point is at $E_{2}, E_{3}$, the manufacturer and the retailer would be in the similar situations; that is, only one oligarchy is operating, and another oligarchic retailer withdraws from competition. This seldom exists in reality even if there are great market potentials and huge profits. So the system is also unstable at these two points. (3) When the Nash equilibrium point is at $E_{4}$, it means that the marginal profit for the manufacturer and the retailer would be zero, both parties will realize their respective profits maximization at this point, the market would be in equilibrium, and its stability is subject to condition (12).

\section{Numerical Simulation}

We try to know the relationship between various factors in the model by means of numerical simulation for better understanding of the dynamic characteristics in market competition. On the basis of actual competitive situation, we hold a view that it is more convenient for the retailer to recycle products at lower costs than the manufacturer.

$$
\begin{aligned}
s & =0.7, \\
c_{m} & =2, \\
c_{t} & =1, \\
G_{m} & =G_{r}=8
\end{aligned}
$$

4.1. The Relationship between the Stability of the Equilibrium Point and the System Parameters. According to the judgment condition (12), Figure 2 shows the stable region for Nash equilibrium point $E_{4}$ with respect to the price adjustment speeds $\alpha_{1}, \alpha_{2}$. When the values for price adjustment speed $\alpha_{1}, \alpha_{2}$ falls within the area in the chart, regardless of the retailer's initial pricing, the final result of the long-term game will stabilize the price of the two retailers at the Nash equilibrium point.

Figure 3 shows the impact of different proportions of recycled products from different channels on the stability domain of the system. As can be seen from Figure 3, when $s=0.3$ it means that more products are recycled from the manufacturer, and the retailer would adopt a relatively fierce price competition strategy for its certain competitive advantage. This relatively frequent price adjustment will maintain the system in stability. It is the same case: when $s=0.9$, more products are to be recycled from the retailer and the manufacturer will gain more opportunities for price adjustment.

By the means of 2-D Bifurcation diagram we make analysis on the types of system bifurcation, the periodic behavior of the solution, and the path leading to chaos. Firstly, we use the adjustment factor of price input as the bifurcation parameter. Figure 4 shows the two-dimensional bifurcation diagram of the system. Brown area is used to

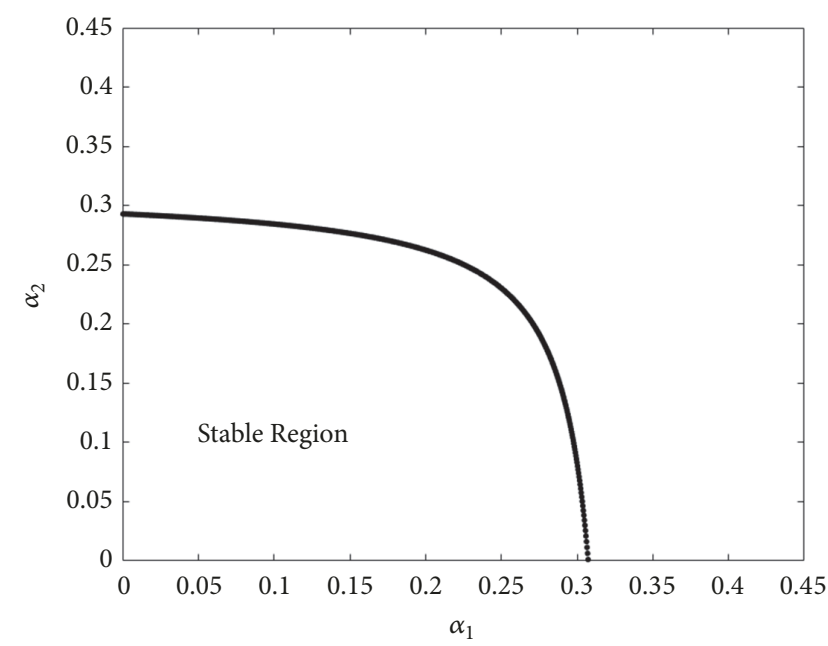

FIGURE 2: Local stable region of the Nash equilibrium point about $\left(\alpha_{1}, \alpha_{2}\right)$.

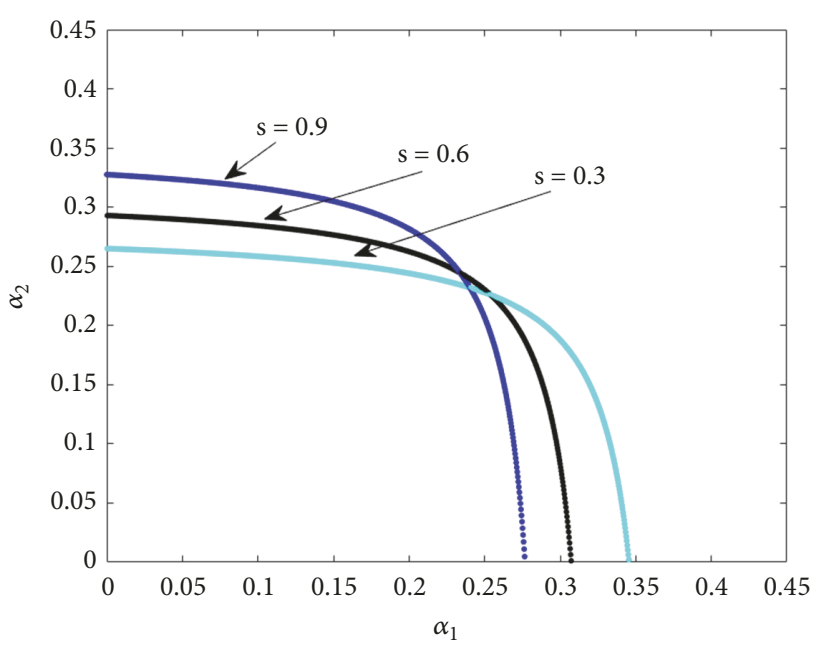

FIGURE 3: Attraction domain of the system.

represent the stability domain of the system that is called 1cycle solution, light blue area for 2-cycle solution domain, red area for 3-cycle solution domain, dark blue area for 4cycle solution domain, black area for 5-cycle solution domain, yellow area for 6-cycle solution domain, and purple area for 7-cycle solution domain; pink area indicates 8-cycle solution domain, gray area indicates chaotic region of the system, and white area indicates that system variables overflow with no meaning. Figure 4 shows that the faster the price adjustment speed is (that is, the more frequent the price adjustment is), the more unstable the whole system will be, and the market will be prone to chaos. Figure 4 shows that the system can enter into chaos situation in two ways: one way is to go toward chaos through the double-cycle bifurcation channel composed with those areas which would be represented by light blue, dark blue, and pink; this way is also called flip bifurcation; the second way toward chaos is to go through odd cycle which is composed with areas represented by red 


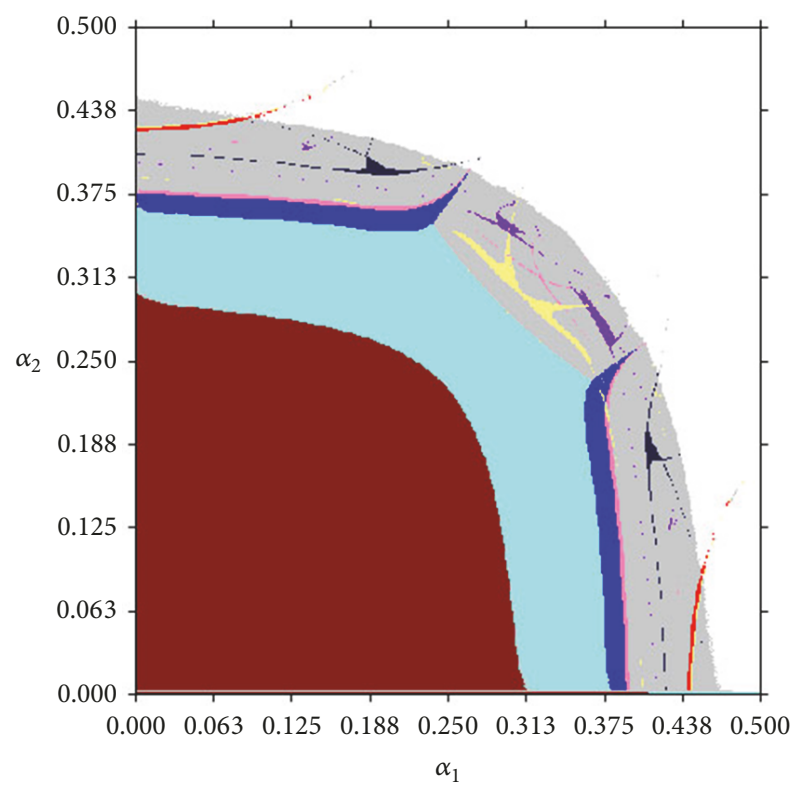

FIGURE 4: The 2-D bifurcation diagram of the system with $\left(\alpha_{1}, \alpha_{2}\right)$.

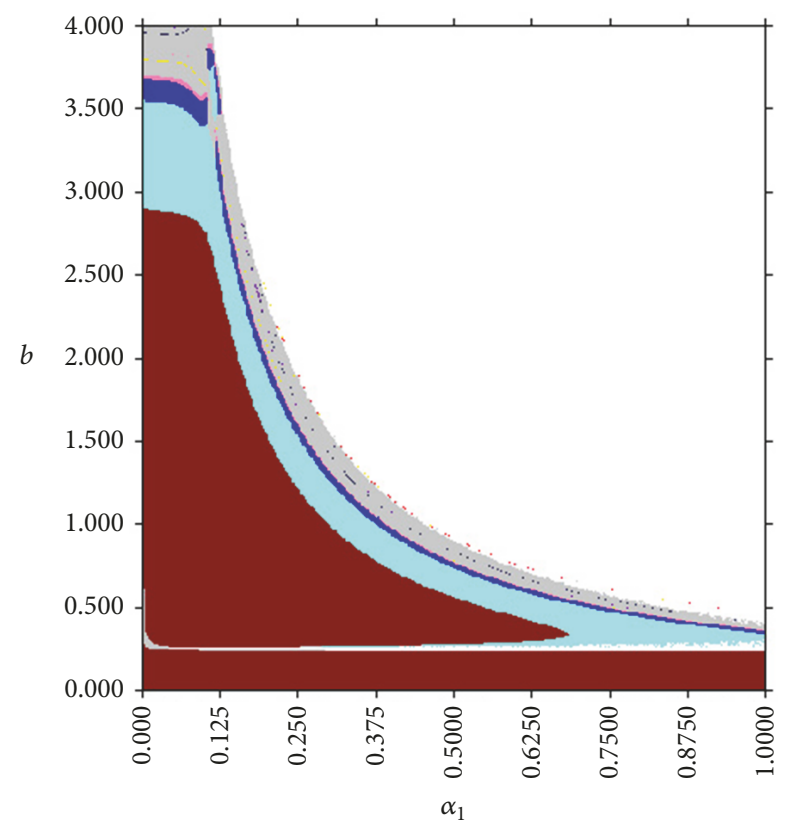

FIGURE 5: Impact of consumer sensitivity on recycling prices on system stability.

and black. From Figure 4 we can also find intermittent odd cycle points.

Figure 5 shows a two-dimensional bifurcation which indicates the relation between the consumer's sensitivity to the recycling price and the manufacturer's recycling price adjustment rate $\alpha_{1}$. From Figure 5 we can conclude that the more sensitive the consumer is to the recycling price, the more unstable the system will be. Figure 6 shows a twodimensional bifurcation diagram which shows the relation between the price cross-elasticity among channels and adjustment rate $\alpha_{1}$ for the manufacturer's recycling price. Figure 6

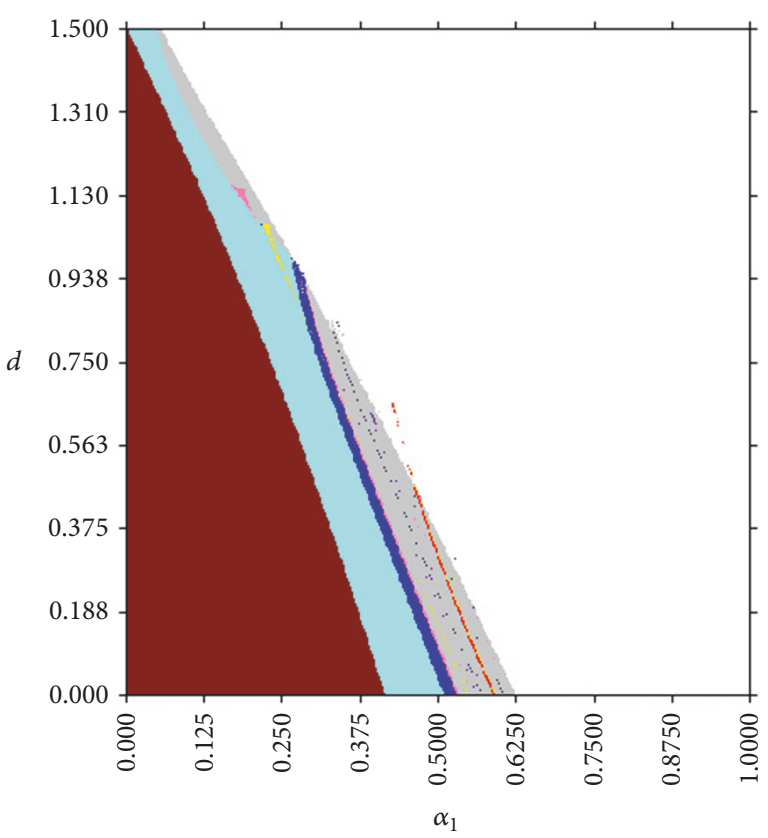

FIGURE 6: Impact of price cross-elasticity between two channels on system stability.

tells us that when the consumer is more sensitive to price differences between channels, the system will become more unstable. In the same way, when the consumer is more sensitive to price factors, for the aspect of the manufacturer, the strategic space for increasing competitive advantage through price adjustment will become smaller. These three factors, which include the degree of the consumer's sensitivity to the recycling price, the price cross-elasticity between channels, and the regularities of adjustment speed $\alpha_{2}$ for the retailer's recycling price, have been similar to those in Figures 5 and 6 . In this aspect further statements would be unnecessary.

For the purpose of further analysis on the dynamics of the system, the influences of parameters on attractors' basin of attraction will be studied through the critical curves. LC (critical curves) is defined as the locus of points which have two (or even more) coincident rank-1 preimages. These preimages are located on a set and are called $\mathrm{LC}_{-1}$. LC can subdivide the plane into different regions in accordance with the number of their preimage (see [Puu,1996] for more details); $\mathrm{LC}_{-1}$ belongs to the points where the value of Jacobian determinant is 0 .

$$
L C_{-1} \subseteq J_{0}=\left\{\left(p_{m}, p_{r}\right) \subset R^{2} \mid \operatorname{det} J\left(p_{m}, p_{r}\right)=0\right\} .
$$

System (5) gives definition of the representation $M$ and we could get the conclusion like $L C=M\left(L C_{-1}\right)$. In reality the price should be nonnegative; that is, $p_{m}, p_{r}>0$, so we could define one feasible zone:

$$
R_{1}=\left\{\left(\left(p_{m}, p_{r}\right) \subset R^{2} \mid p_{m}>0, p_{r}>0\right)\right\} .
$$

Figure 7 shows basin of attraction of the attractor (equilibrium point) when $\alpha_{1}=0.1, \alpha_{2}=0.1$, where the gray region satisfies the condition that, along with it, its one-step iteration 


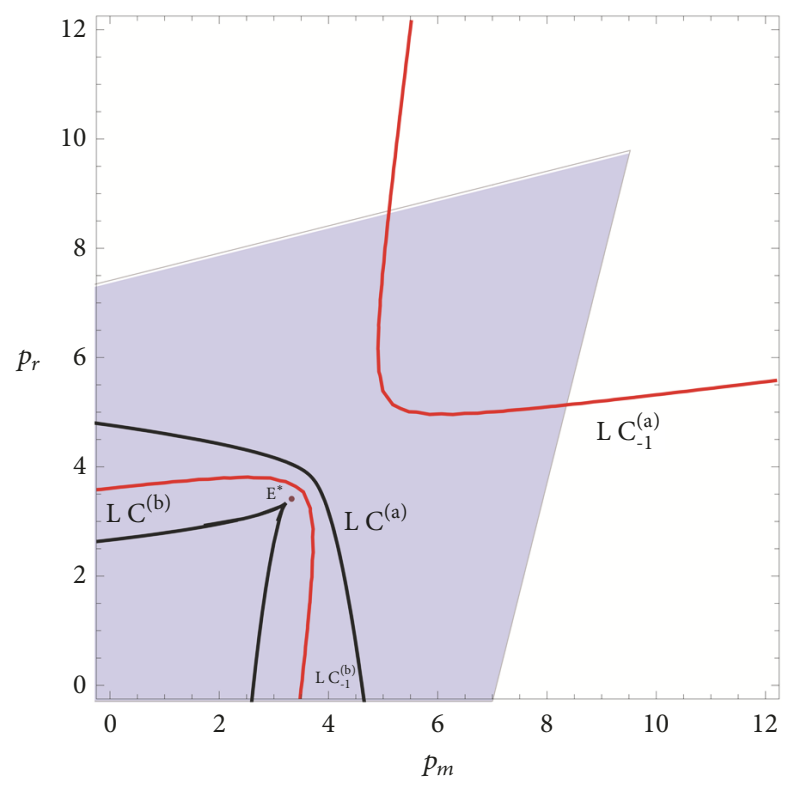

Figure 7: The basin of attraction when $\alpha_{1}=0.1, \alpha_{2}=0.1$.

also belongs to $\mathrm{R}_{1}$ when red lines are $\mathrm{LC}_{-1}$ and black lines are LC (the same below). From Figure 7, we know that the one-step iteration of gray region is surrounded by LC and coordinate axes; then it belongs to the gray region and the gray region is trapping set. Moreover, the simulations show that there is no coexisting attractor and the gray region is the feasible basin of attraction. Figure 8 shows basin of attraction of the attractor (equilibrium point) when $\alpha_{1}=0.4, \alpha_{2}=0.1$. By comparing Figures 7 and 8, we find that when $\alpha_{1}$ increases, the basin of attraction will decrease in the direction of $p_{m}$ and make no change in the direction of $p_{r}$ with reduction of the entire basin of attraction. At the same time, we notice that when $\alpha_{1}$ increases, the Nash equilibrium point of the system will change from one to another attracting domain, which is also called a singular attractor. This is the feature which indicates that the whole system will enter into chaos.

4.2. Chaotic Characteristics of Market Competition. For better understanding of market competition behaviors after the system has entered into chaos, we will make analysis on the complexity of the long-term game for system (5) by using these analysis tools for chaotic characteristics; these tools include price bifurcation diagram, chaotic attractor, and initial value sensitivity.

Figure 9 shows the bifurcation diagram of the system along with changes of manufacturer price adjustment $\alpha_{1}$. From Figure 9, we can conclude that when the manufacturer's price adjustment speed is low, the system will be stable at the Nash equilibrium point $(3.253,3.413)$. However, as the manufacturer' price adjustment $\alpha_{1}$ continues to increase, pricing will get the bifurcation for the first time at the point where $\alpha_{1}=0.299$, and two equilibrium solutions would also emerge. Furthermore, when $\alpha_{1}=0.374$ the pricing will enter into the quadruple-cycled bifurcation and then enter into the eight-fold cycle, and eventually the entire competition system will become chaotic. Figure 9 shows us clearly that when the

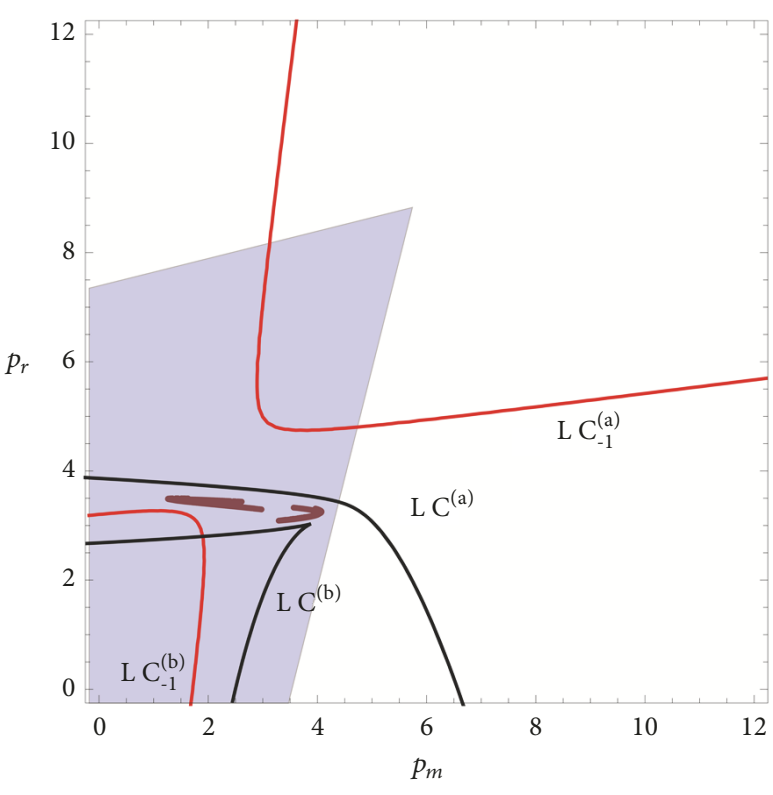

Figure 8: The basin of attraction when $\alpha_{1}=0.4, \alpha_{2}=0.1$.

system is chaotic, the pricing for both the manufacturer and the retailer will become very difficult because it would be hard and difficult for them to determine their optimal pricing in accordance with the conditions of the competitors and the market competitions.

Singular attractor, the result of interaction between the overall stability and local instability of the system, is another feature of system chaos. It has self-similarity and a fractal structure. Figure 10 shows us the formation of these singular attractors in this model.

When the system is in the chaotic state, any changes of the initial value will have a greater impact on the result, even if these changes are very tiny and small. That is to say, the evolution result of the system has an extremely sensitive dependence on the initial value, which is the socalled Butterfly Effect. The red lines area in Figure 11 indicates that when $\alpha_{1}=0.1$ (that is to say, the system being in a steady state), the price is changing along with the time. The blue lines area indicates that when $\alpha_{1}=0.42$ (that is to say, the system being in a chaotic state), the price will make changes along with the time. We can clearly see that, compared with that pricing in the stable situation for the system, the pricing decision will become uncertain, disordered, and unpredictable with the system being in chaotic situation. Figure 12 shows the evolution of the manufacturer's recycling price with time changes when the system is in chaos (when $\left.\alpha_{1}=0.42\right)$ and the manufacturer's initial pricing is 1 and 1.01 , respectively. We can see that even if the initial value is only slightly different, when the time goes on, the process for price competition will become quite different through a long period of evolution.

4.3. Influence of Chaos on System Performance. Figure 13 makes comparison for the profit changes along with the time when the system is in the steady state and the chaotic state, respectively. We find that when the system is in a stable 


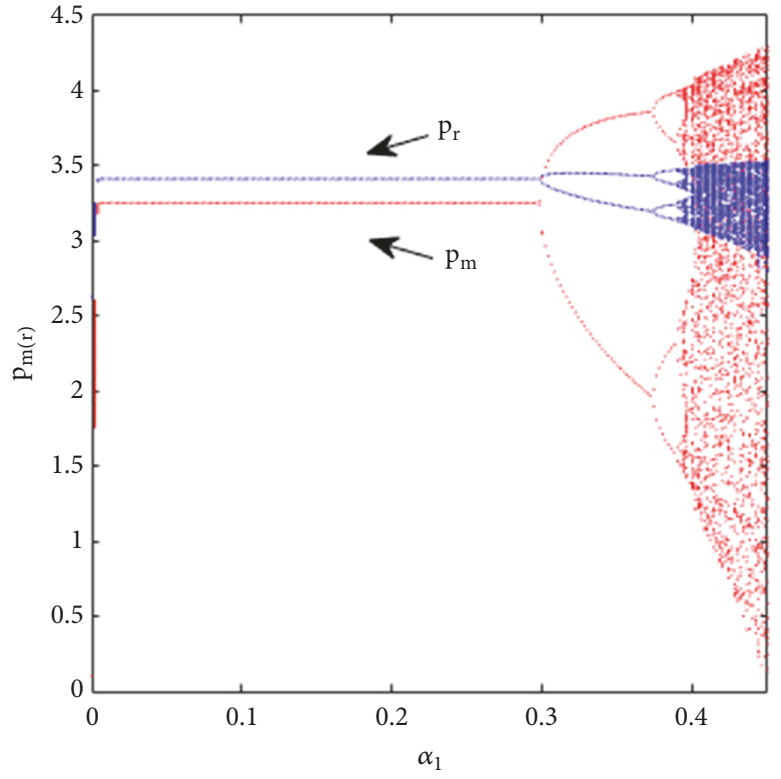

(a)

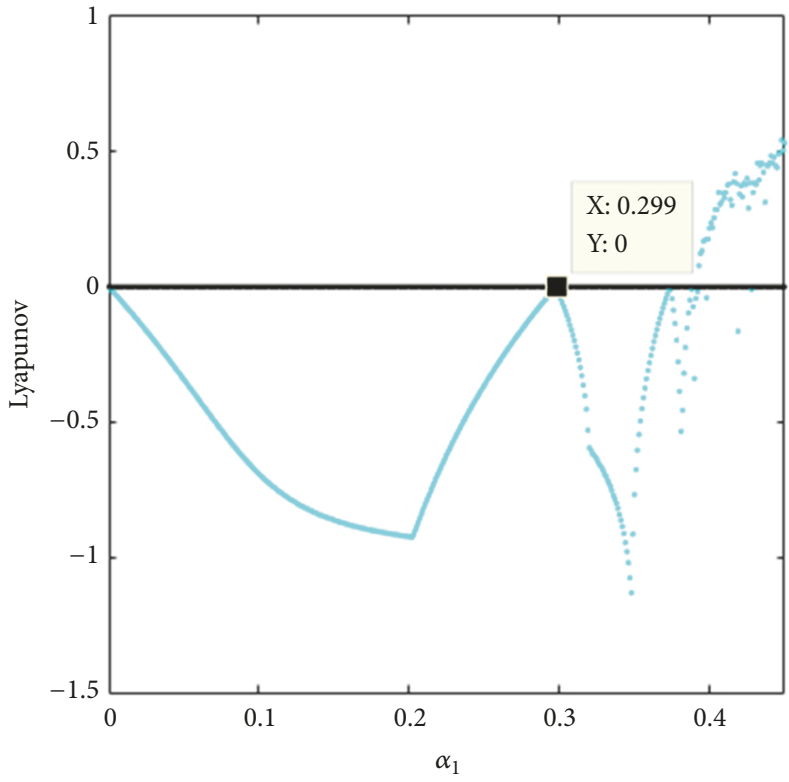

(b)

Figure 9: Bifurcation diagram and Lyapunov exponents with $\alpha_{1}$ when $\alpha_{2}=0.1$. (a) Bifurcation diagram. (b) Lyapunov exponents.

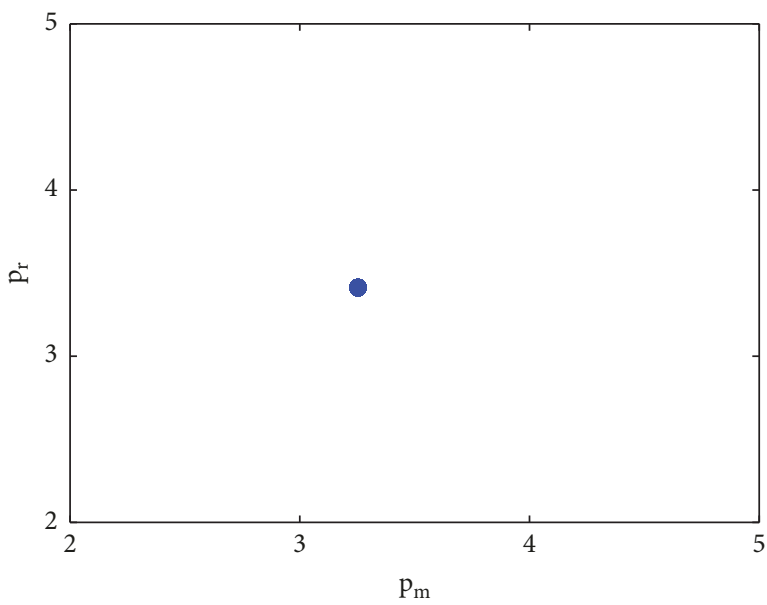

(a)

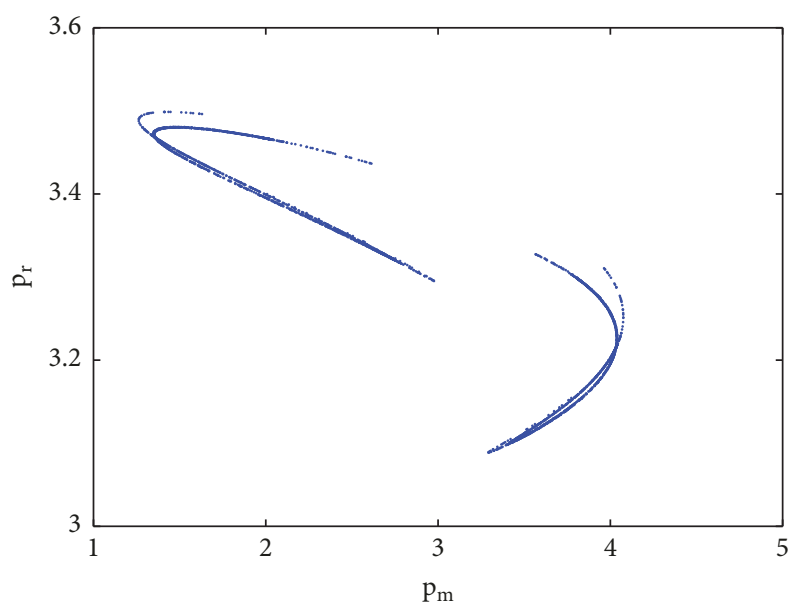

(c)

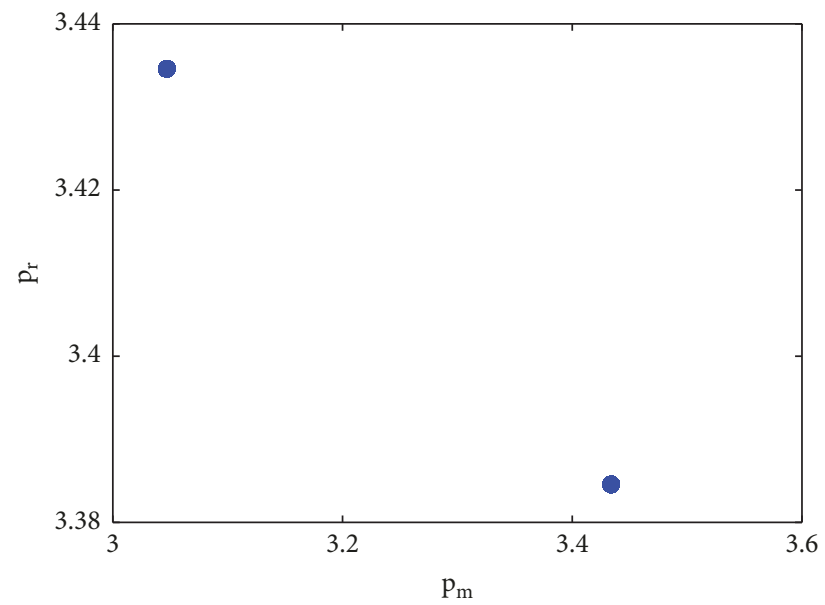

(b)

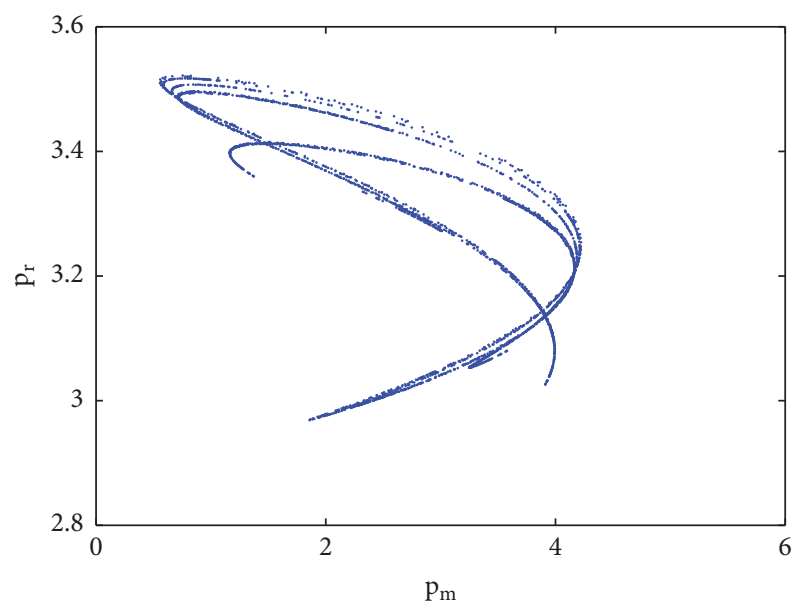

(d)

FIGURE 10: Attractors of the system get changes with the increase of $\alpha_{1}$ : (a) $\alpha_{1}=0.1$. (b) $\alpha_{1}=0.3$. (c) $\alpha_{1}=0.4$. (d) $\alpha_{1}=0.43$. 


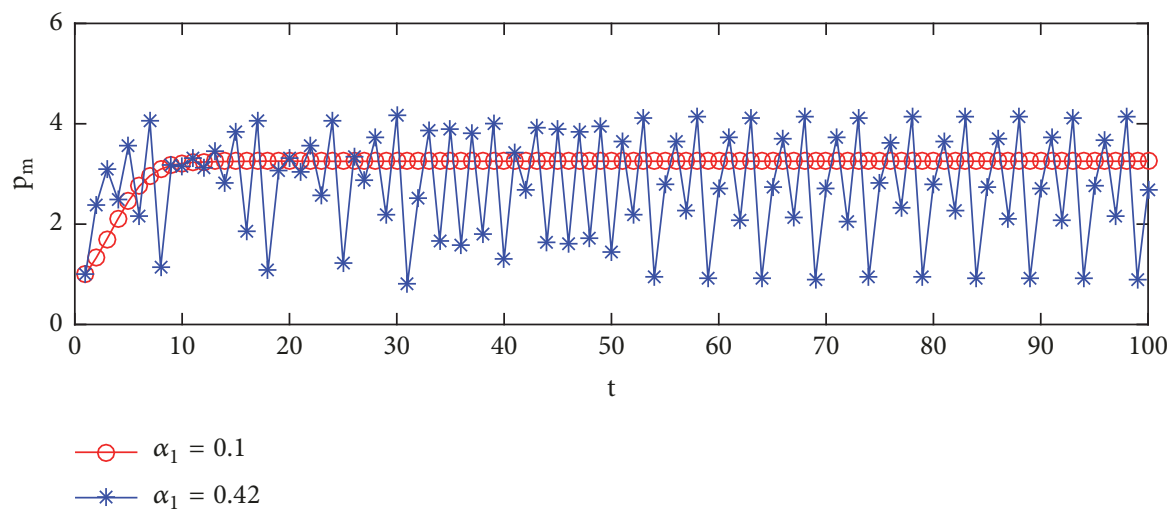

(a)

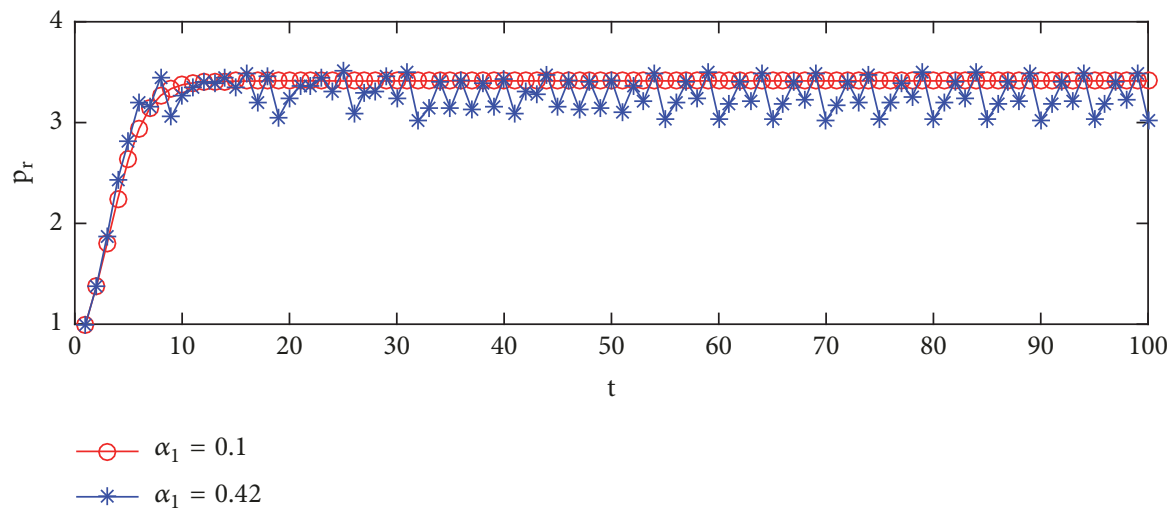

(b)

FIGURE 11: Power spectrum of the system when $\alpha_{1}=0.42, \alpha_{2}=0.1$ : (a) change for $p_{m}$ along with the time; (b) change for $p_{r}$ along with the time.

state, the price competition can be stabilized to the Nash equilibrium point after a finite number of games playing. At this point, each retailer's profit will be stable; while when the system is in a chaotic state, the retailer's profit changes will become disordered. Clearly this is the situation neither manufacturers nor retailers would expect. Table 1 shows us the average profit of the retailer in different periods. We can see that when the system has changed from the stable period into the chaos state through the stages of bifurcations of double cycle, quadruple cycle, and octuple cycle, the overall profit of the market would have dropped down. This indicates that chaos breaks the order of the market and causes the loss of the operational efficiency for the entire economic system.

4.4. Chaos Control. From the above analysis, we can learn that, in the complex price competition, the market equilibrium is only a short-term process in which many changeable factors are involved. For example, when the retailer speeds up price adjustments, the market will change from the stable state to chaotic one. Once the market enters into chaos, neither the manufacturer nor the retailer could predict the market competition, the pricing will become disordered, and the market will not achieve an effective equilibrium. The above analysis also shows that the retailer would get lower profits in this state than in the balanced state. In the actual market competition, retailers will adopt various competition strategies for profit maximization after longterm price games. Price competition is their favorite and most frequently used competition method, while excessive price competition would easily lead to inefficiency and disorder for the market and bring losses to retailers. Therefore, it is very important to take timely control measures for the market's returning to a stable equilibrium.

The method of parameter adaptation is employed to control the system effectively (see the study by Huang [30, $38])$ to control system (5). We assume that the original dynamical system is $p(t+1)=g_{1}\left(p_{m}(t), p_{r}(t)\right)$, and adaptive adjustment mechanism is employed to control the recycling price. The governing equations are as follows:

$$
\begin{gathered}
p_{m}(t+1)=(1-K) * g_{1}\left(p_{m}(t), p_{r}(t)\right)+K p_{m}(t) \\
p_{r}(t+1)=(1-K) * g_{2}\left(p_{m}(t), p_{r}(t)\right)+K p_{r}(t)
\end{gathered}
$$

In the control system (16), $\mathrm{K}$ is the adjusting parameter. We notice that when $\mathrm{K}=0$, system (16) would degenerate into the uncontrolled system (5). As we can see from Figure 14, when different values for the control parameter $\mathrm{K}$ are chosen, the system will get controlled. When control parameter $\mathrm{K}$ is equal to 0.65 , that is, $K=0.65$, no matter what $\alpha_{1}$ is, the system will be controlled in the double cycle; when $\mathrm{K}$ is equal to 0.7 , that is, $K=0.7$, the system will be completely controlled in a stable orbit. Figure 15 shows the system price 
TABLE 1: Profits when the system is at different times.

\begin{tabular}{lcccc}
\hline $\begin{array}{l}\text { Different } \\
\text { periods }\end{array}$ & Stable period & $\begin{array}{c}\text { Two-period-doubling } \\
\text { bifurcation }\end{array}$ & $\begin{array}{c}\text { Four-period-doubling } \\
\text { bifurcation }\end{array}$ & $\begin{array}{c}\text { Chaotic } \\
\text { period }\end{array}$ \\
\hline$\pi_{m}$ & 7.4796 & 7.2040 & 6.5778 & 6.1118 \\
\hline$\pi_{r}$ & 12.7450 & 12.9026 & 13.2846 & 13.6014 \\
\hline$\sum \pi_{i}$ & 20.2247 & 20.1066 & 19.8624 & 19.7132 \\
\hline
\end{tabular}

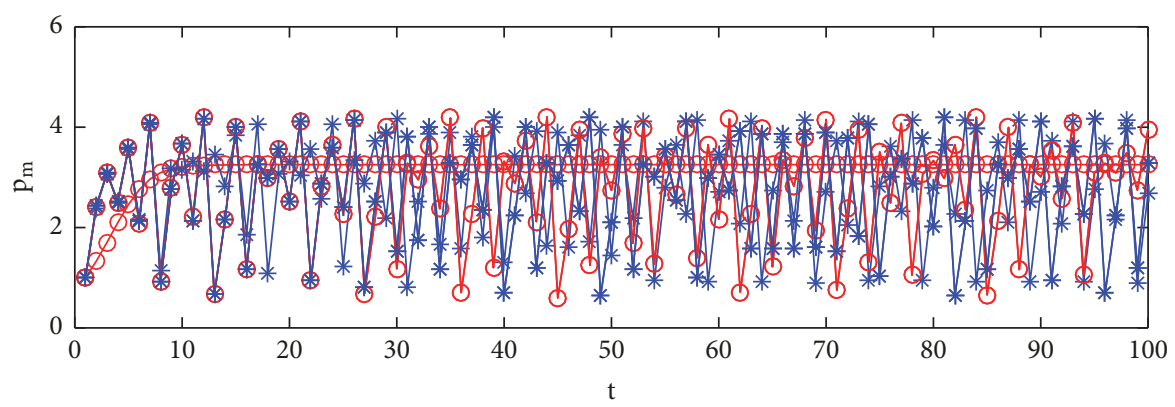

$$
\begin{aligned}
& -\mathrm{p}_{\mathrm{m}}=1 \\
& \text { * } \mathrm{p}_{\mathrm{m}}=1.01
\end{aligned}
$$

(a)

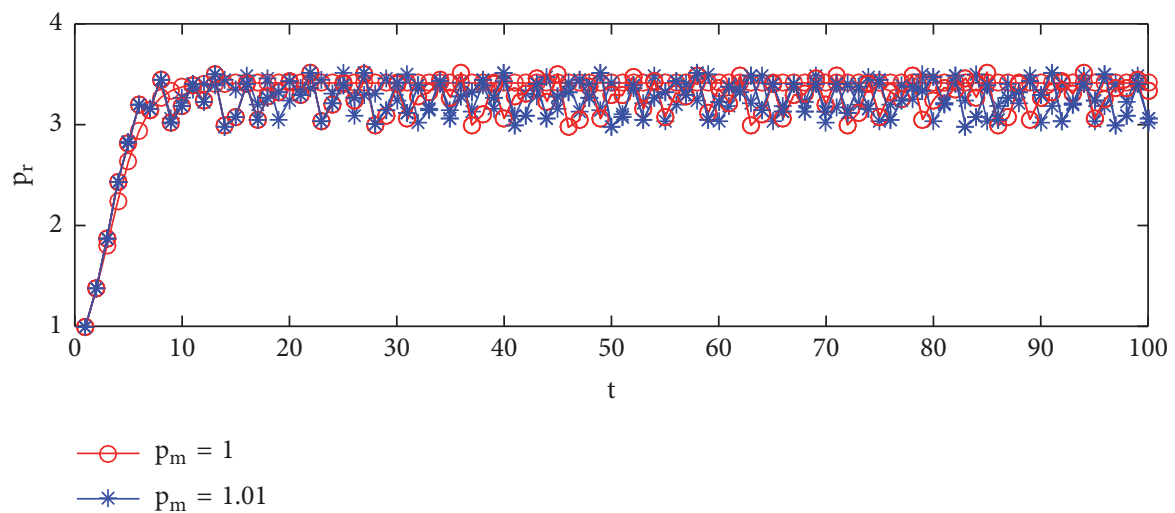

(b)

FIGURE 12: Sensitivity dependence to initial condition when $p_{m}=1$ and $p_{m}=1.01$ : (a) change for $p_{m}$ along with the time; (b) change for $p_{r}$ along with the time.

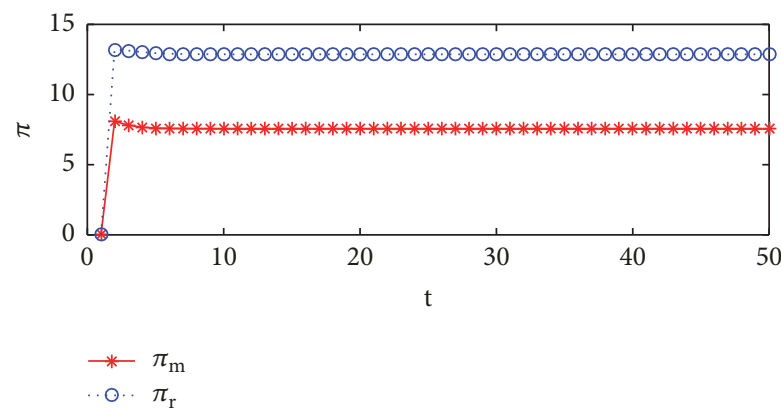

(a)

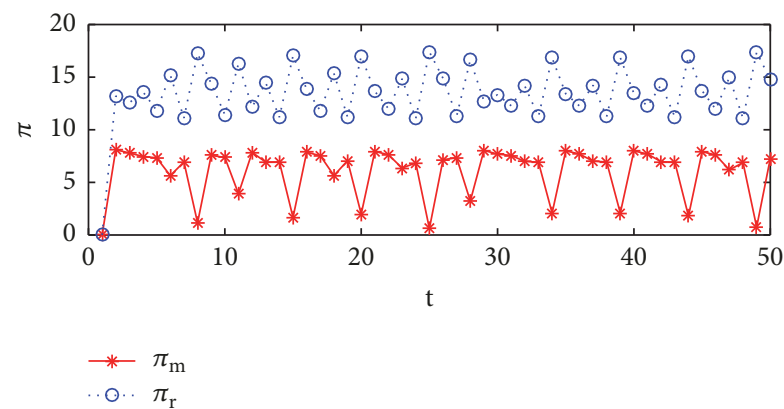

(b)

FIGURE 13: Changes for profits in different periods: (a) steady state; (b) chaotic state. 


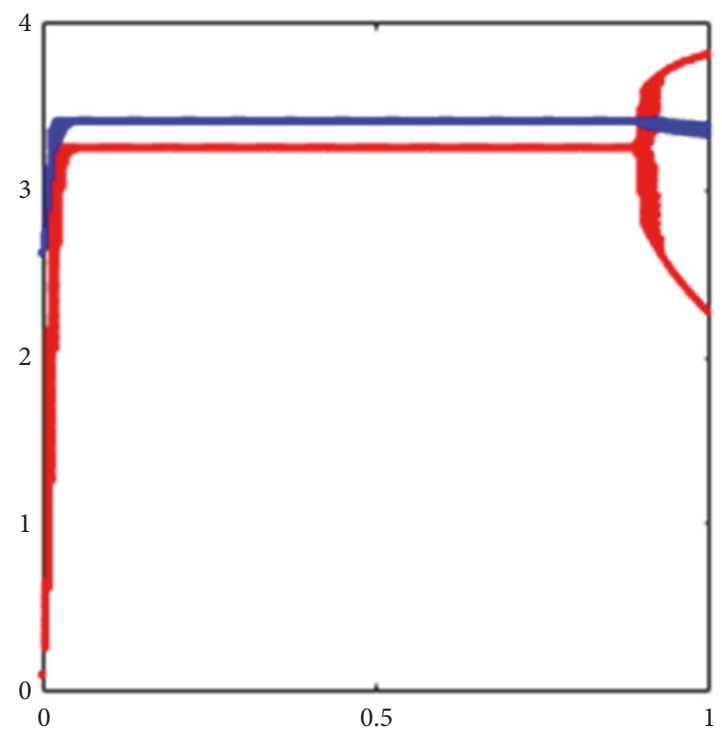

(a) $\mathrm{K}=0.65$

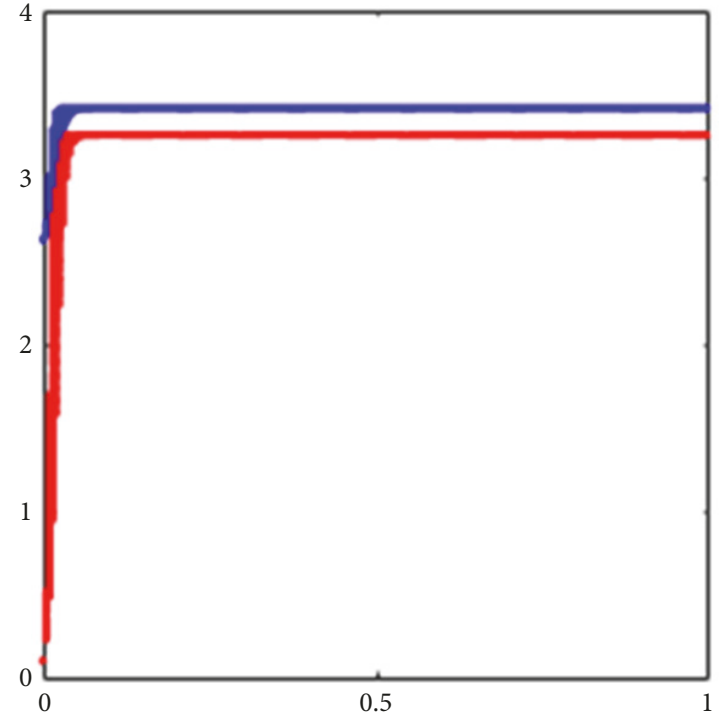

(b) $\mathrm{K}=0.7$

Figure 14: Bifurcation diagram with respect to diffident $K$ : (a) $K=0.65$; (b) $K=0.7$.

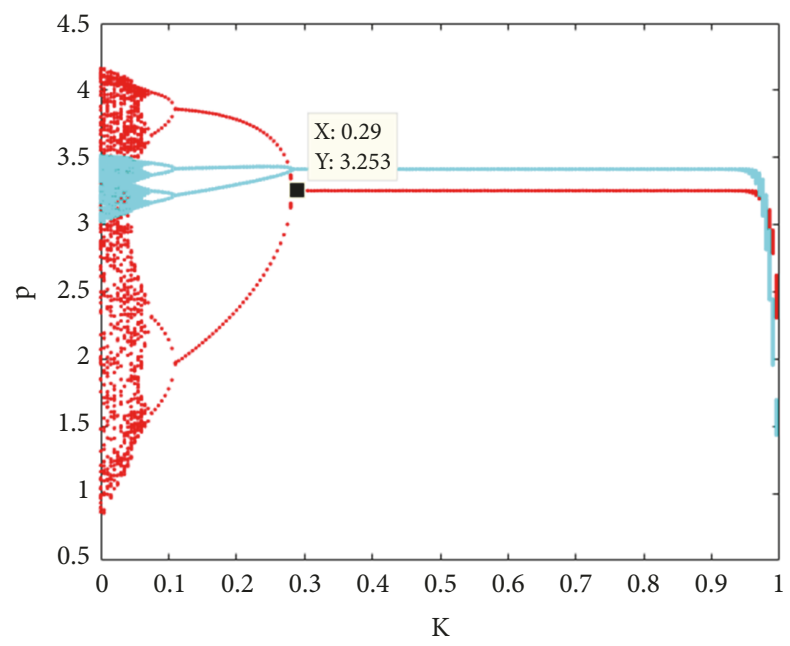

FIGURE 15: Bifurcation diagram with change of the control parameter $\mathrm{K}$.

changes together with the control parameter $\mathrm{K}$ when the system is already in a chaotic state. From Figure 15, we can see that when $\mathrm{K}=0.29$, the chaotic system will be recontrolled at the equilibrium point. For better understanding of the controlling effect of the control parameter K, Figure 16 gives the variations of the even price with changes of different control parameters $\mathrm{K}$. We found that when $\mathrm{K}=0.32$, after a period of game playing, the fluctuations of the recycling price will decrease and the price will return to a stable state. In the real market, the control parameter $\mathrm{K}$ can be regarded as an external interference of the government in the recycling price. When the market is led to the chaotic state because of the realization of profit maximization from the manufacturer and the retailer, the government will make effective interference in price competition. From another perspective, the control parameters $\mathrm{K}$ could also be regarded as some kind of the retailer's learning for the market and the performance of its own self-adaptive ability. When the retailer gets the awareness of the market chaos which will bring great damages to his profits, he will take the initiatives to make his own price adjustment on the basis of market information analysis.

\section{Conclusion}

In this paper, for the study of the long-term competitive behaviour of the manufacturer and retailer in the process of recycling products, we established one recycling price game model which consists of one manufacturer and one retailer. Analysis was made on the stability of the equilibrium point in the game model with the result that three unstable bounded equilibrium points and a Nash equilibrium point with local stability have been founded. The stability conditions of the Nash equilibrium point have got deeper research. The complexity behaviour of the system is studied by using bifurcation diagram, maximum Lyapunov exponent diagram, chaotic attractor, and power spectrum. Finally, we make effective control of the chaotic behaviours in the system by the application of the control method for variable feedback. Through the research we can get the following conclusions:

(1) System stability depends on the value of each parameter. When the adjustment speed for the recycling price is too fast, the system will show periodic bifurcation and chaos.

(2) Consumers' differences for recycling prices and prices differences between channels will have an impact on the system stability. Studies have shown that the more sensitive consumers are to the price factors, the much smaller the system's stability space will become. Price adjustment, also referring to the adjustment of price competition strategy for advantages, whether or not being employed by the manufacturers or retailers, will bring the market into chaos. 


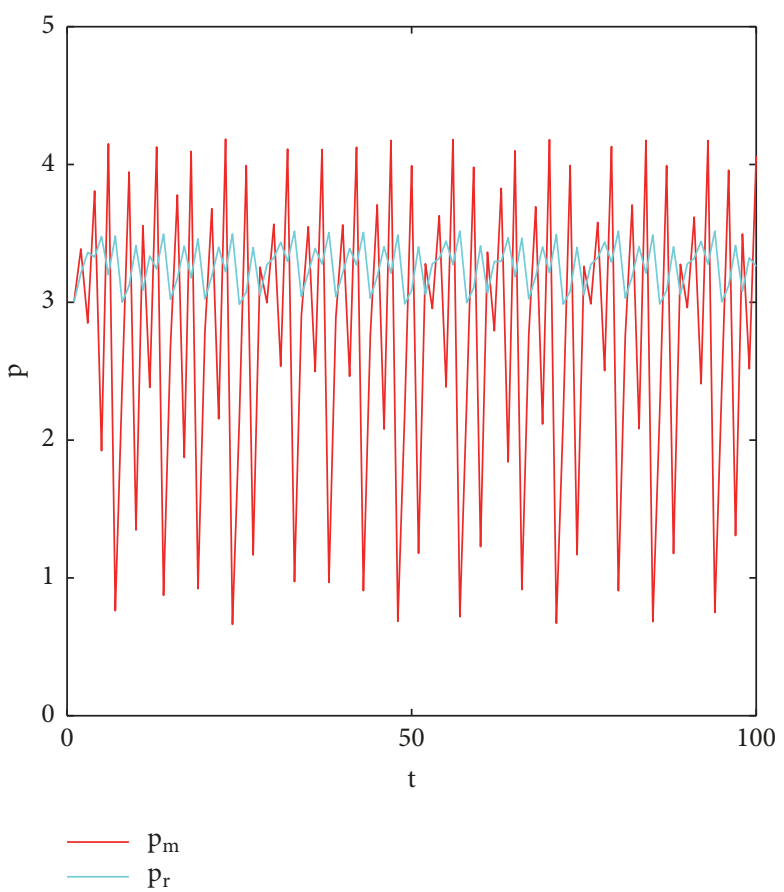

(a)

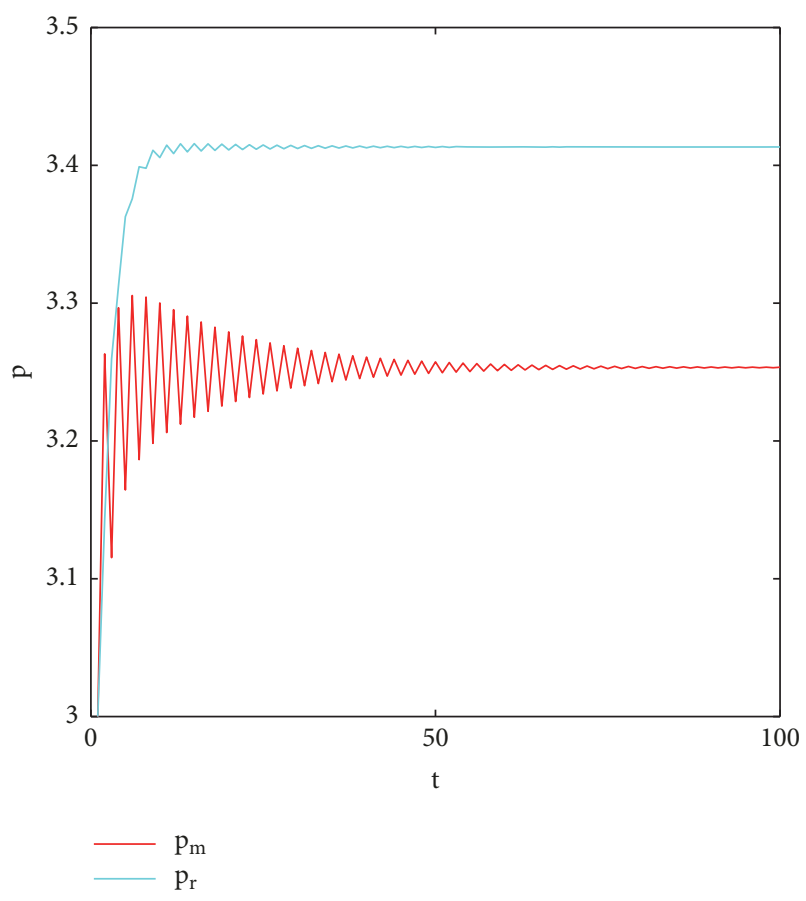

(b)

Figure 16: Power spectrum for price: (a) K=0; (b) $K=0.3$.

(3) We find that when the recycling price is kept stable at the Nash equilibrium point, the system would realize its highest performance (that means profit maximization). When the system is in periodic bifurcation or chaotic state, even the extremely small price changes could cause the great fluctuations in market evolution behaviours and in the event lead to profit losses for the whole system.

\section{Data Availability}

No data were used to support this study.

\section{Conflicts of Interest}

The authors declare that they have no conflicts of interest.

\section{Acknowledgments}

The research was supported by China Postdoctoral Fund (No. 2016M602155), Ministry of Education Humanities and Social Sciences Project (No.18YJCZH081), Scientific Research Projects in Shandong Universities (No. J18RA055), Talent Introduction Project of Dezhou University (No. 2015skrc05), and The Subject of Bidding for Key Disciplines in the 13th Five-Year Plan of Dezhou University (No. 3010040235).

\section{References}

[1] R. C. Savaskan, S. Bhattacharya, and L. N. Van Wassenhove, "Closed-loop supply chain models with product remanufacturing," Management Science, vol. 50, no. 2, pp. 239-252, 2004.
[2] R. C. Savaskan and L. N. van Wassenhove, "Reverse channel design: the case of competing retailers," Management Science, vol. 52, no. 1, pp. 1-14, 2006.

[3] C.-H. Chuang, C. X. Wang, and Y. Zhao, "Closed-loop supply chain models for a high-tech product under alternative reverse channel and collection cost structures," International Journal of Production Economics, vol. 156, pp. 108-123, 2014.

[4] G. Ferrer and J. M. Swaminathan, "Managing new and remanufactured products," Management Science, vol. 52, no. 1, pp. 1526, 2006.

[5] G. Ferrer and J. M. Swaminathan, "Managing new and differentiated remanufactured products," European Journal of Operational Research, vol. 203, no. 2, pp. 370-379, 2010.

[6] I. Karakayali, H. Emir-Farinas, and E. Akcali, "An analysis of decentralized collection and processing of end-of-life products," Journal of Operations Management, vol. 25, no. 6, pp. 1161-1183, 2007.

[7] J. Adda and R. Cooper, "Balladurette and juppette: a discrete analysis of scrapping subsidies," Journal of Political Economy, vol. 108, no. 4, pp. 778-806, 2000.

[8] W.-M. Ma, Z. Zhao, and H. Ke, "Dual-channel closed-loop supply chain with government consumption-subsidy," European Journal of Operational Research, vol. 226, no. 2, pp. 221-227, 2013.

[9] M. Huang, M. Song, L. H. Lee, and W. K. Ching, "Analysis for strategy of closed-loop supply chain with dual recycling channel," International Journal of Production Economics, vol. 144, no. 2, pp. 510-520, 2013.

[10] M. Zu-Jun, N. Zhang, Y. Dai, and S. Hu, "Managing channel profits of different cooperative models in closed-loop supply chains," Omega, vol. 59, pp. 251-262, 2016. 
[11] T. Maiti and B. C. Giri, "A closed loop supply chain under retail price and product quality dependent demand," Journal of Manufacturing Systems, vol. 37, pp. 624-637, 2015.

[12] A. A. Cournot, Recherches sur les principes mathématiques de la théorie des richesses par Augustin Cournot, chez L. Hachette, 1838.

[13] J. Bertrand, "Review of Theorie mathematique de la richessesociale and of Recherches sur les principles mathematiques de la theorie des richesses," des Savants, vol. 67, pp. 499-508, 1883.

[14] R. D. Theocharis, "On the stability of the Cournot solution on the oligopoly problem," The Review of Economic Studies, vol. 27, no. 2, pp. 133-134, 1960.

[15] D. Rand, "Exotic phenomena in games and duopoly models," Journal of Mathematical Economics, vol. 5, no. 2, pp. 173-184, 1978.

[16] T. Puu, "The chaotic monopolist," Chaos, Solitons \& Fractals, vol. 5, no. 1, pp. 35-44, 1995.

[17] T. Puu and M. R. Marín, "The dynamics of a triopoly Cournot game when the competitors operate under capacity constraints," Chaos, Solitons \& Fractals, vol. 28, no. 2, pp. 403-413, 2006.

[18] G. I. Bischi and M. Kopel, "Equilibrium selection in a nonlinear duopoly game with adaptive expectations," Journal of Economic Behavior \& Organization, vol. 46, no. 1, pp. 73-100, 2001.

[19] G.-I. Bischi and F. Lamantia, "Nonlinear duopoly games with positive cost externalities due to spillover effects," Chaos, Solitons \& Fractals, vol. 13, no. 4, pp. 701-721, 2002.

[20] H. N. Agiza, A. S. Hegazi, and A. A. Elsadany, "Complex dynamics and synchronization of a duopoly game with bounded rationality," Mathematics and Computers in Simulation, vol. 58, no. 2, pp. 133-146, 2002.

[21] E. Ahmed and A. S. Hegazi, "On dynamical multi-team and signaling games," Applied Mathematics and Computation, vol. 172, no. 1, pp. 524-530, 2006.

[22] E. Ahmed, M. F. Elettreby, and A. S. Hegazi, "On Puu's incomplete information formulation for the standard and multi-team Bertrand game," Chaos, Solitons \& Fractals, vol. 30, no. 5, pp. 1180-1184, 2006.

[23] A. A. Elsadany, "Dynamics of a delayed duopoly game with bounded rationality," Mathematical and Computer Modelling, vol. 52, no. 9, pp. 1479-1489, 2010.

[24] T. Li and J. Ma, "Complexity analysis of dual-channel game model with different managers' business objectives," Communications in Nonlinear Science and Numerical Simulation, vol. 20, no. 1, pp. 199-208, 2015.

[25] T. Li and J. Ma, "Complexity analysis of the dual-channel supply chain model with delay decision," Nonlinear Dynamics, vol. 78, no. 4, pp. 2617-2626, 2014.

[26] L. Qiu-Xiang, Z. Yu-Hao, and H. Yi-Min, "The complexity analysis in dual-channel supply chain based on fairness concern and different business objectives," Complexity, vol. 2018, 2018.

[27] Q. Li, X. Chen, and Y. Huang, "Complexity and entropy analysis of a multi-channel supply chain considering channel cooperation and service," Entropy, vol. 20, no. 12, p. 970, 2018.

[28] J. Ma, H. Ren, M. Yu, and M. Zhu, "Research on the complexity and chaos control about a closed-loop supply chain with dual-channel recycling and uncertain consumer perception," Complexity, vol. 2018, Article ID 9853635, 13 pages, 2018.

[29] Y. Guo and J. Ma, "Research on game model and complexity of retailer collecting and selling in closed-loop supply chain," Applied Mathematical Modelling, vol. 37, no. 7, pp. 5047-5058, 2013.
[30] W. Huang, "Stabilizing nonlinear dynamical systems by an adaptive adjustment mechanism," Physical Review E: Statistical, Nonlinear, and Soft Matter Physics, vol. 61, no. 2, pp. R1012R1015, 2000.

[31] G. Chen, Controlling Chaos and Bifurcations in Engineering Systems, CRC press, 1999.

[32] E. Ott and M. Spano, "Controlling chaos," AIP Conference Proceeding, vol. 375, no. 1, pp. 92-103, 1996.

[33] R. Lima and M. Pettini, "Suppression of chaos by resonant parametric perturbations," Physical Review A: Atomic, Molecular and Optical Physics, vol. 41, no. 2, pp. 726-733, 1990.

[34] E. R. Hunt, "Stabilizing high-period orbits in a chaotic system: the diode resonator," Physical Review Letters, vol. 67, no. 15, pp. 1953-1955, 1991.

[35] K. Pyragas, "Continuous control of chaos by self-controlling feedback," Physics Letters A, vol. 170, no. 6, pp. 421-428, 1992.

[36] U. E. Kocamaz, H. Taşkın, Y. Uyaroğlu, and A. Göksu, "Control and synchronization of chaotic supply chains using intelligent approaches," Computers \& Industrial Engineering, vol. 102, pp. 476-487, 2016.

[37] A. Goksu, U. E. Kocamaz, and Y. Uyaroglu, "Synchronization and control of chaos in supply chain management," Computers \& Industrial Engineering, vol. 86, pp. 107-115, 2015.

[38] W. Huang, "Theory of adaptive adjustment," Dynamics in Nature and Society, vol. 5, no. 4, pp. 247-263, 2000. 


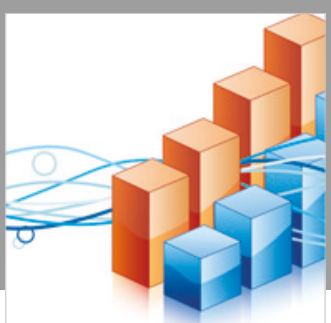

Advances in

Operations Research

\section{-n-m}
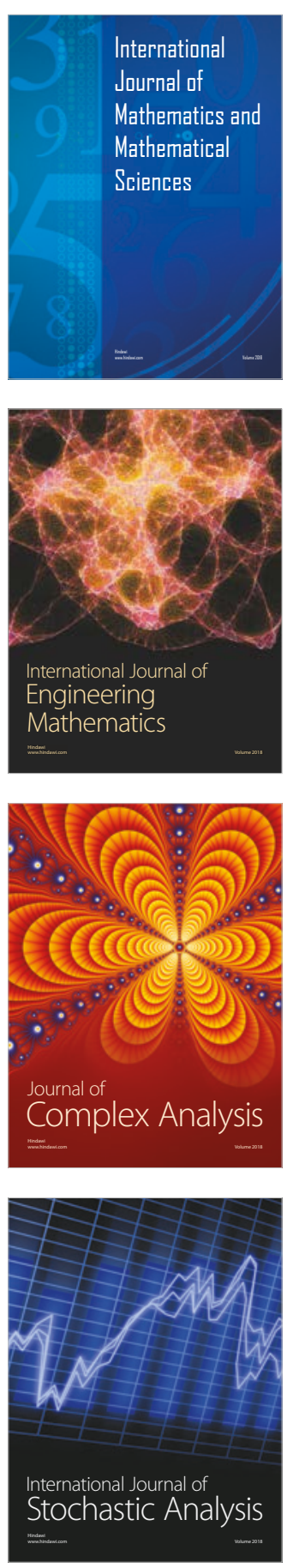
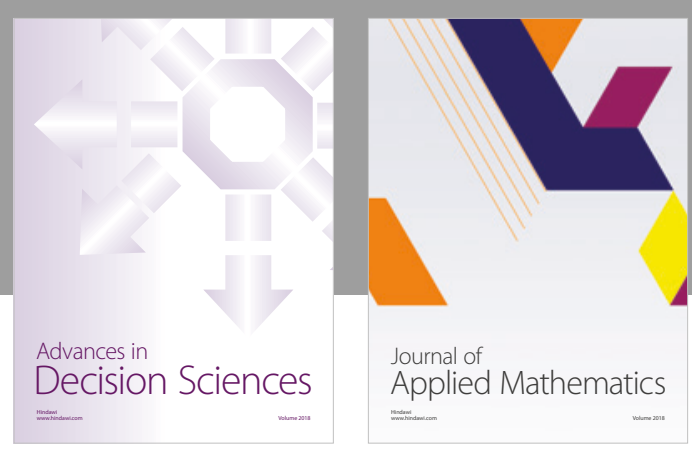

Journal of

Applied Mathematics
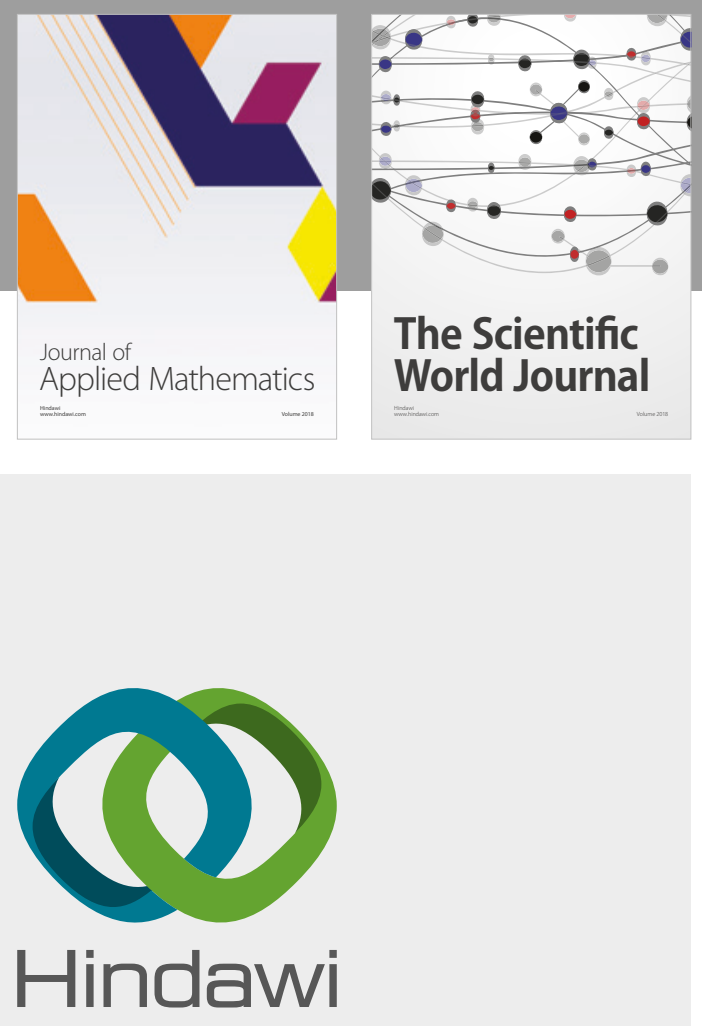

Submit your manuscripts at

www.hindawi.com

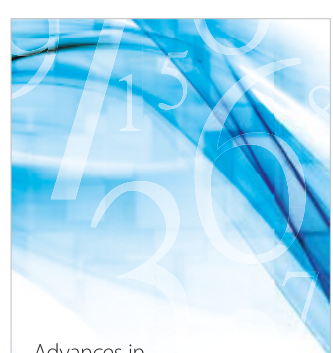

Advances in
Numerical Analysis
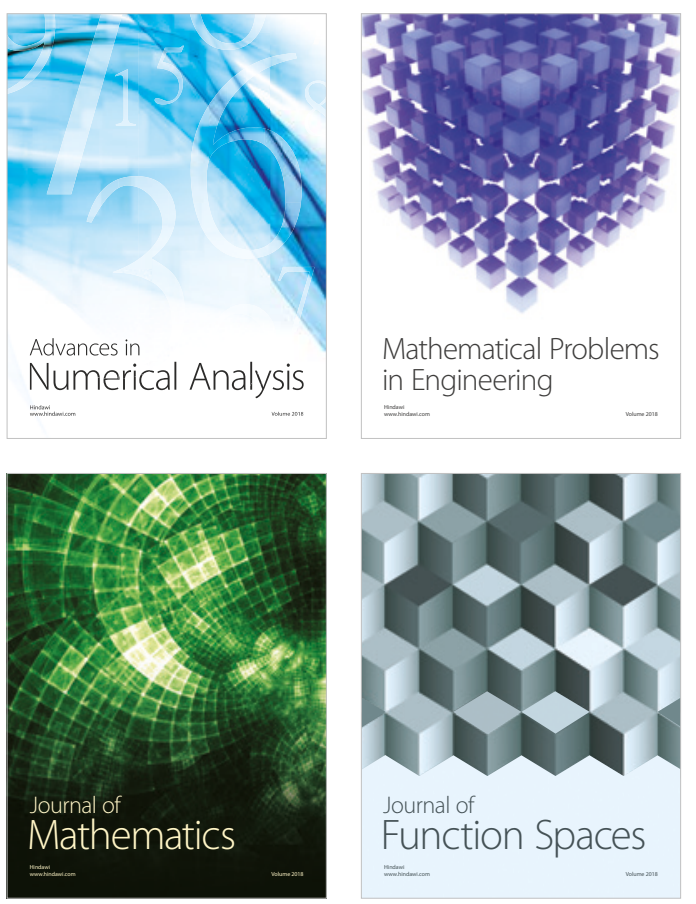

Mathematical Problems in Engineering

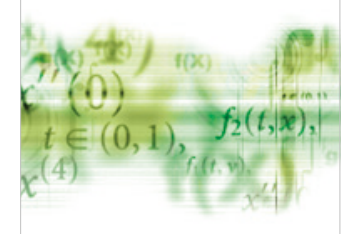

International Journal of

Differential Equations

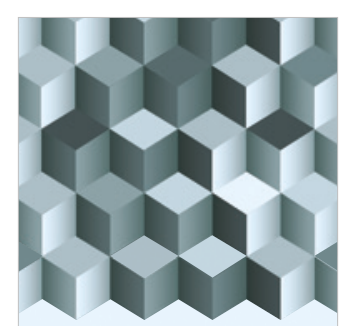

Journal of

Function Spaces
The Scientific

World Journal

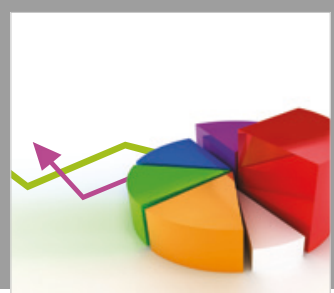

Journal of

Probability and Statistics
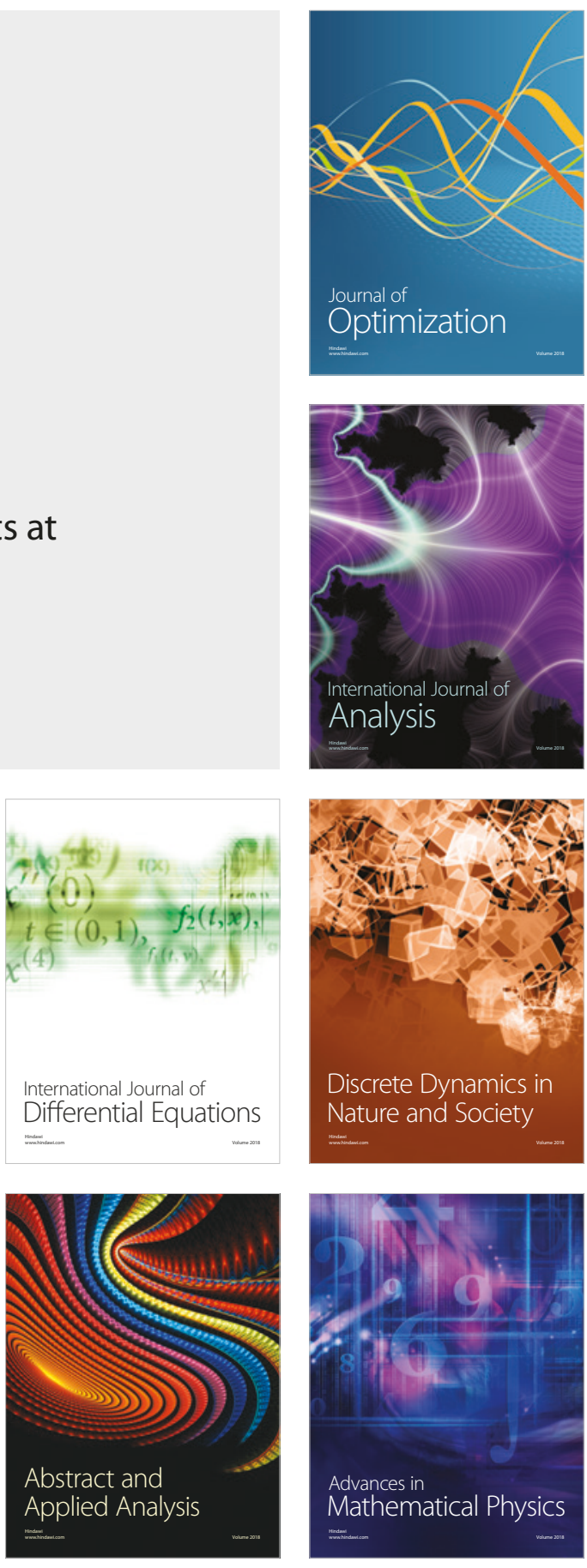